\title{
Future of Higher Education: Emotionally Intelligent and Mindful?
}

\author{
Jami L. Cotler ${ }^{1}$, Dmitry Burshteyn ${ }^{2}$, Beth DeAngelis ${ }^{3}$, Rachael Mahar ${ }^{1}$ \\ ${ }^{1}$ Computer Science Department, Siena College, USA, ${ }^{2}$ Psychology Department, Siena \\ College, USA, ${ }^{3}$ Women's Center, Siena College, USA.
}

\begin{abstract}
The purpose of this study was to investigate the effect of using the RESET model on Emotional Intelligence, Resilience, and Empathy of students registered for a software engineering senior capstone computer science course. Thirty-seven undergraduate students participated in this study during 2017-18 academic year. The participants were taught emotional intelligence and mindfulness skills encompassed by the RESET model. Most of the students completed both Pre and Post EQi 2.0 and Connor-Davidson Resilience (RISC-25) scales. Our results indicate statistically significant pre to post changes in overall emotional intelligence $t(32)=3.071, p<.004$, empathy $t(32)=4.143, p<.0001$, and resilience $t(24)=2.366, p<.026$. This quasi experiment is the first step in assessing the efficacy of the RESET Model in higher education. More controlled experiments will follow. These results support the notion that mindfulness practices coupled with emotional intelligence training lead to increases in resilience, overall emotional intelligence and empathy in college students.
\end{abstract}

Keywords: Emotional Intelligence; Higher Education; Mindfulness; Software Engineering; Empathy; Resilience. 


\section{Introduction}

The purpose of this study was to investigate the effect of using the RESET model on Emotional Intelligence, Resilience, and Empathy in a software engineering senior capstone computer science course.

Agile software development is a methodology used where the emphasis is on creating usable code as quickly as possible. This software development method allows software engineers to quickly change direction due to changes in customer requirements. Students in a full year capstone Software Engineering course worked closely with an outside client to develop original software. In this capstone experience creative solutions evolve through close collaboration of self-organizing teams using the agile software development methodology. This approach puts a premium on communication and teamwork (Cotler, et al., 2017; Singh, Singh, \& Sharma, 2012). Part of our paradigm integrated into our agile development practice is emotional intelligence (EI) to help foster the growth of these critical skills. Mindfulness which correlates with the growth of the main pillars of EI was used in the study as a foundational construct (Cotler, et al, 2017).

EI has been largely defined by the construct that has been developed, validated, and used to measure it. In the study presented in this paper the EQi 2.0 Model was used to assess the five foundational components of EI. These include self-expression, self-perception, stress management, decision making, and interpersonal skills. Much of the research in the area of EI in higher education has been focused on whether students possess these skills (Bonesso et al.2013; Davidson, 2012). At the same time, fewer studies have discovered how undergraduate students' EI can be improved and what evidence based curricula are most effective in fostering development in these areas (Alexander, 2014; Bonesso, et al. 2013; Conley, 2015; Lin, Lee, Hsu \& Lin, 2011; Pool \& Qualter, 2014; Salami, 2010).

\section{Emotional Intelligence: Definition and Importance in Higher Education}

The publisher of the EQ-1 2.0 model, Multi-Health Systems (MHS, 2019) defines Emotional Intelligence as a set of emotional \& social skills that influence the way we perceive and express ourselves, develop and maintain relationships, cope with challenges and use emotional information in an effective and meaningful way. The exciting aspect of EI is that unlike IQ and personality it is something that can be learned and developed (Goleman, 2004). Multiple studies have shown the importance and benefits to higher education students of developing these EI skills such as better grades (Nelson \& Nelson, 2003, Zeidner et al., 2009), increased workplace performance especially when working in teams (Bradberry, 2014; Eswara, 2019), leadership talent (Bradberry, 2014; Goleman, 2004, 2013; Goleman et al., 2013), overall job satisfaction (Sener, Demirel, \& Sarlak, 2009), and increased earning potential (Bradberry, 2014; Momm, Blickle, Liu, Wihler, 
Kholin, \& Menges, 2014). Students graduating with these skills are often sought after by employers especially in technical organizations (Bradberry, 2014; Majid \& Mulia, 2011). For example, Google relies more on EI then grades or school attended when interviewing candidates for positions (NACE, 2015; Thygesen, 2014). Only 42.5\% of the employers that were surveyed in Job Outlook 2018 reported that graduating students have the necessary emotional intelligence skills (professionalism) necessary to succeed in the workplace (NACE, 2018). These findings highlight the importance of teaching these critical skills to undergraduate college students. While evidence highlighting the importance of emotional intelligence to undergraduate students continues to grow, the perception of employers is that students are not graduating with these skills (NACE, 2018), primarily because they are not being taught as part of their undergraduate experience (Beard \& Schwieger, 2008; Jobes, 2015; Scott-Bracey, 2011).

\subsection{Influence of Mindfulness on Emotional Intelligence}

Shapiro et al (2015) describe mindfulness as "bringing full awareness into the present moment." Researchers continually report the multiple benefits of mindfulness practices, many of which have a positive relationship with EI (Brown \& Ryan, 2003). Regular mindfulness practice strengthens the ability to understand our own emotions (Brown, Ryan, \& Creswell, 2007), to regulate and control emotions (Cahn \& Polich, 2006), and develop the ability to detect and understand the emotions of others (Brown et al., 2007). Further, due to neuroplasticity, mindfulness practices have been shown to change the composition of the brain (Tan, 2012). One study using magnetic resonance imaging pre-post a mindfulness program found positive changes in the mindfulness group when compared with the control group, in locations of the brain involved in functions important to EI such as emotional regulation, self-referential processing, and perspective taking (Hölzel, Carmody, Vanqel, Congleton, Yerramsetti, Gard, \& Lazar, 2010).

\section{The Study}

\subsection{Participants}

This study was conducted in the capstone software engineering course during the 2017 2018 academic year. This study was conducted at a small liberal arts college (approximately 3,200 students) and included 37 undergraduate students enrolled in a fullyear senior capstone software engineering course. All students were computer science majors in their final year of study, where thirty were male $(81 \%)$ and seven were female $(19 \%)$. 


\subsection{Instruments}

The EQi 2.0 assessment tool was selected to measure emotional intelligence at the start of the fall semester 2017 and again at the end of the spring semester 2018. This psychometric assessment tool has strong internal consistency $(\alpha=.69-.86)$ and test-retest reliability (1month $\mathrm{r}=0.85$ and 4-month $\mathrm{r}=0.75$ ). Further, this instrument is used widely (over one million world-wide) and offers a comprehensive individual student report with feedback with strategies for enhancing personal EI skills (MHS, 2019). The instructor of the software engineering course is a certified practitioner of EQi 2.0.

The Connor-Davidson Resilience (RISC-25) scale was used to measure resilience. According to Davidson JRT (2018), CD-RISC has been validated and successfully used in multiple experimental studies. This measure has a high predictive validity and high testretest reliability $(\mathrm{r}=0.87)$. SPSS was used to perform the statistical analysis.

\subsection{Procedure}

All students were pre-tested for both EI and Resilience using the EQi 2.0 and ConnorDavidson Resilience (RISC-25) scales respectively. Integrated directly into the curriculum for this full-year course were experiential emotional intelligence interventions using the RESET model (Recognizing and regulating Emotions through Social and Emotional Teambased learning supported with mindfulness), (Cotler, 2016; Cotler, et al, 2017). Based on the RESET model, mindfulness was integrated directly into the start of class and was followed up with an assignment for individual practice outside of class. At the end of the year, all students were post-tested for both EI and Resilience using the EQi 2.0 and ConnorDavidson Resilience (RISC-25) scale.

\section{Results}

The results of the study showed statistically significant growth in the areas of student resilience, overall emotional intelligence and empathy. As shown in Table 1, the following results were obtained for Connor-Davidson Resilience scale. The mean (M) of 75.40 with the standard deviation (SD) of 11.979 was observed for pre-test while $\mathrm{M}=79.92$ and $\mathrm{SD}=$ 12.265 was observed for post-test condition. A paired samples t-test was conducted to analyze the differences between pre- and post-tests and resulted in a $\mathrm{t}(24)=2.366, \mathrm{p}<.026$, indicating statistically significant increase in resilience between the pre-and post- test. EQi 2.0 scores resulted in the $\mathrm{M}=104.55$ with $\mathrm{SD}=13.024$ for the pre-test and $\mathrm{M}=110.30$ with $\mathrm{SD}=15.306$ for the post-test condition. A paired sample t-test yielded a $\mathrm{t}(32)=3.071$, $\mathrm{p}<.004$, indicating statistically significant increase in EQi 2.0 scores from pre to post-test. A statistically significant increase was also observed for Empathy scores with a $\mathrm{t}(32)=4.143, \mathrm{p}<.0001$ and corresponding $\mathrm{M}=107.06, \mathrm{SD}=13.246$ for pre-test, and 
$\mathrm{M}=114.58, \mathrm{SD}=9.418$ for the post-test. These initial results support the notion that mindfulness practices coupled with emotional intelligence training leads to increases in resilience, overall emotional intelligence and empathy in college students.

Table 1: Quantitative Results

\begin{tabular}{llll}
\hline Measure & Pre Test & Post Test & t-test results \\
\hline Connor-Davidson Resilience Scale & $\mathrm{M}=75.40$ & $\mathrm{M}=79.52$ & $\mathrm{t}(24)=2.366$ \\
& $\mathrm{SD}=11.979$ & $\mathrm{SD}=12.265$ & $\mathrm{p}<.026$ \\
Overall EQi 2.0 Scores & $\mathrm{M}=104.55$ & $\mathrm{M}=110.30$ & $\mathrm{t}(32)=3.071$ \\
& $\mathrm{SD}=13.024$ & $\mathrm{SD}=15.306$ & $\mathrm{p}<.004$ \\
Empathy Scores & $\mathrm{M}=107.06$ & $\mathrm{M}=114.58$ & $\mathrm{t}(32)=4.143$ \\
& $\mathrm{SD}=13.246$ & $\mathrm{SD}=9.418$ & $\mathrm{p}<.0001$ \\
\hline
\end{tabular}

\subsection{Sample Student Reflection}

As a student who has completed two computer science classes that incorporated mindfulness and emotional intelligence into the course, I have noticed a difference in my mindset towards creating software. In the fall semester of 2018 I was enrolled in two of these courses, Human Computer Interaction (HCI) and Software Engineering I. In the beginning of the semester every student took the Myers-Briggs Type Indicator, an EQi 2.0 assessment and had a meeting to discuss our individual results with our instructor. I used this experience to self reflect, understand other personality types and learn how to design considerate software. Throughout the course we were taught how to build empathy with target users to understand their specific needs and goals. We were also taught how to design for different personality types and even users with disabilities.

Along with improving my emotional intelligence, I also practiced mindfulness. At the beginning of almost every class in HCI we spent a couple minutes doing a reset meditation where our instructor would guide us to concentrate on an anchor, sometimes our breath or sometimes an outside noise. Being a college student where it's hard to relax during the semester, these couple minutes before class were appreciated to just take a second to breathe and collect myself. I found myself more relaxed and focused for the rest of the class on the days we practiced meditation than the ones we did not.

Understanding and developing my emotional intelligence and practicing mindfulness has not only changed my professional attitude when designing software but it has also bled into my personal life. I have become more aware of other's emotions and give gratitude more often than I was before taking these computer science courses. 


\section{Discussion}

Our results point towards potential effectiveness of the RESET model in higher education, and specifically in computer science. These results support the notion that mindfulness practices coupled with emotional intelligence training may lead to increases in resilience, overall emotional intelligence and empathy in college students. The authors would like to note that this is a quasi experimental study with no control group. This type of research is very difficult but important to conduct as it is limited by curriculum structure in the U.S. where it is rare to have students enrolled in a one-year long undergraduate capstone courses. There are also important gender and personality type variables (Reynolds, et al., 2016) that may have played a role in this study and make our results even more noteworthy. The Computer Science major in the U.S. has one of the largest gender disparities across science, technology, engineering and mathematics (Master, et al., 2016). In this male dominated field, often characterized by students who choose it because they are more comfortable interacting with machines than with other people (Cheryan, et al., 2015) seeing such a dramatic pre to post improvement in EI and empathy scores for such students is very encouraging. Therefore, despite some methodological limitations, this experiment is an important step forward in demonstrating the model's potential impact on higher education.

\section{References}

Alexander, B. (2014). Higher Education in 2024: Glimpsing the future. Educause Review Online. Retrieved from: http://www.educause.edu/ero/article/higher -education-2024glimpsing-future

Austin, E., Saklofske, D., \& Egan, V. (2005). Personality, well-being and health correlates of trait emotional intelligence, Personality and Individual Differences, 38(3), Pages 547558, ISSN 0191-8869, https://doi.org/10.1016/j.paid.2004.05.009.

Beard, D. \& Schwieger, D. (2008). Integrating soft skills assessments through university, college and programmatic efforts at an AACSB accredited institution. Journal of Information Systems Education, 19(2).

Bonesso, S., Gerli, F., Barzotto, M., \& Comacchio, A. (2013) The emotional intelligence approach in higher education. The case of the "Ca' Foscari Competency Centre", ICEI Conference Proceedings, International Society for Emotional Intelligence, Convegno: 4th International Congress on Emotional Intelligence (ICEI), Sep 8-10 (Articolo in Atti di convegno)

Bradberry, T. (2014). Emotional Intelligence - EQ. Forbes: Leadership. Retrieved from: http://www.forbes.com/sites/travisbradberry /2014/01/09/emotional-intelligence/

Brown, K. \& Ryan, R. (2003). The Benefits of Being Present: Mindfulness and its Role in Psychological Well-Being. Journal of Personality and Social Psychology 84(4) 822-848.

Brown, K., Ryan, R., Creswell, J. (2007). Mindfulness: Theoretical Foundations and Evidence for its Salutary Effects. Psychology Inquiry, 18(4), 211-237. 
Cahn, B. \& Polich, J. (2006). Meditation states and traits: EEG, ERP, and Neuroimaging Studies. Psychology Bulletin, 132(2), 180-211.

Cheryan, S., Master, A., \& Meltzoff, A. (2015). Cultural Sterotypes as Gatekeepers: increasing girls' interest in computer science and engineering by diversifying stereotypes. Frontiers in Psychology https://doi.org/10.3389/fpsyg.2015.00049

Conley, C. S. (2015). SEL in higher education. In J. A. Durlak, C. E. Domitrovich, R. P. Weissberg, \& T. P. Gullotta (Eds.), Handbook of Social and Emotional Learning: Research and Practice, New York: Guilford, 197-212.

Cotler, J. L. (2016). The impact of online teaching and learning about emotional intelligence, Myers Briggs personality dimensions and mindfulness on personal and social awareness. Unpublished doctoral dissertation, State University of New York at Albany.

Cotler, J., DiTursi, D., Goldstein, I., Yates, J., \& DelBelso, D. (2017). A Mindful Approach to Teaching Emotional Intelligence to Undergraduate Students Online and in Person. Information Systems Education Journal, 15(1), p12-25.

Davidson JRT. Connor-Davidson Resilience Scale (CDRISC) Manual. Unpublished. 0819-2018, accessible at www.cdrisc.com.

Davidson, R., \& McEwen, B. (2012). Social influences on neuroplasticity: stress and interventions to promote well-being. Nature Neuroscience 15, 689-695.

Eswara, P. (2019). Developing your teamwork skills. Inside Higher Ed. Retrieved from: https://www.insidehighered.com/advice/2019/01/28/grad-students-need-improve-theirteamwork-skills-become-more-attractive-employers

Goleman, D. (2004). What makes a leader? Harvard Business Review. Retrieved from: https://hbr.org/2004/01/what-makes-aleader\#

Goleman, D. (2013). The focused leader. Harvard Business Review. Retrieved from: https://hbr.org/2013/12/the-focused-leader

Goleman, D., Boyatzis, R., \& McKee, A. (2013). Primal leadership: Unleashing the power of emotional intelligence. Harvard Business Press.

Hölzel, B., Carmody, J., Vanqel, M., Congleton, C., Yerramsetti, S., Gard, T., \& Lazar, S. (2010). Mindfulness practice leads to increases in regional brain gray matter density. Psychiatry Research Neuroimaging. 191(1), 36-43.

Jobes, N. (2015). Recent college graduates entering workforce fall short on soft skills training. Blasting News. Retrieved http://us.blastingnews.com/business/2015/08/recent-college-graduates-enteringworkforce-fall-short-on-soft-skills-training-00534859.html

Lin, Y., Lee, T., Hsu, S., \& Lin, S. (2011). What causes the emotional intelligence suffered by students at universities and colleges of technology? World Transactions on Engineering and Technology Education, 9(2), 102-108

Majid, S., \& Mulia, R. (2011). Competencies sought by knowledge management employers: Content analysis of online job advertisements. Managing Knowledge for Global and Collaborative Innovations, 8, 317- 326. 
Master, A., Cheryan, S., \& Meltzoff, A. N. (2016). Computing whether she belongs: Stereotypes undermine girls' interest and sense of belonging in computer science. Journal of Educational Psychology, 108(3), 424-437.

Momm, T., Blickle, G., Liu, Y., Wihler, A., Kholin, M., \& Menges, J. (2015). It pays to have an eye for emotions: Emotion recognition ability indirectly predicts annual income. Journal of Organizational Behavior, 36(1), 147-163

Multi-Health Systems (2019). The Complete EQi 2.0 Experience. MHS Systems. Retrieved from: http://downloads.mhs.com/eqi/EQi-Launch-Kit.pdf

NACE Staff (2018). Are College Graduates "Career Ready"? NACE. Retrieved from: https://www.naceweb.org/career-readiness/competencies/are-college-graduates-careerready/

NACE, (2014). Job Outlook Survey, 2015, 36.

Pool, L., \& Qualter, P. (2014). Improving emotional intelligence and emotional self efficacy through a teaching intervention for university students. Learning and Individual Differences 22, 306-312

Reynolds, J., Adams, D.R., Ferguson, R., \& Leidig, P. (2016). The personality of a computing major: It makes a difference. 2016 Proceedings of the EDSIG Conference. ISSN: 2473-3857

Salami, S. D. (2010). Emotional intelligence, selfefficacy, psychological well-being and students attitudes: Implication for quality education. European Journal of Educational Studies, 2(3), 247-257.

Scott-Bracey, P. (2011). An examination of soft skills listed in Texas electronic job postings and undergraduate business information systems syllabi. Dissertation, University of North Texas.

Sener, E., Demirel O. \& Sarlak, K. (2009). The effect of the emotional intelligence on job satisfaction. Studies in Health Technology and Informatics, 146:710:1

Shapiro, S. L., Wang, M. C., \& Peltason, E. H. (2015). What is mindfulness, and why should organizations care about it? Mindfulness in Organizations: Foundations, Research, and Applications, Cambridge University Press.

Singh, A., Singh, K., \& Sharma, N. (2012). Managing knowledge in agile softeware development. International Journal of Advanced Computer Science and Applications (IJACSA), 2(4)

Tan, Chade-Meng (2012). Search inside yourself. New York Harper One.

Thygesen, K. (2014). Why Emotional Intelligence is more important to hiring than you think. FastCompany. Retrieved from: https://www.fastcompany.com/3029306/whyyou-should-make-emotional-intelligence-the-cornerstone-of-your-hiring-strategy 